\title{
Brief Introduction on Australia Early Childhood Teaching Manpower Training Policy and Its Implications for China
}

\author{
Shan-An WANG \\ No.9 Xuefu Avenue, Chongqing University of Education, Chongqing City, China \\ 171264898@qq.com
}

Key words: Australia preschool education; Early childhood education and care; Kindergarten teachers training

\begin{abstract}
Recently, there are many reforms on workforce training in early childhood care and education in Australia, in addition to proposed Early Years Workforce Strategy, Australian also proposes other specific policies such as funding education, the expansion of Additional early childhood education university places, Innovative Early Childhood Workforce Projects. We can learn from the Australian experience to complete kindergarten teachers' professional qualification certification system, and innovative funding models of preschool teacher training.

We know that early education and care programs are important preparation for young children, and that well-trained, qualified teachers and providers are necessary for programs to promote children's development [1].Recently, there are many reforms on workforce training in early childhood care and education in Australia, especially in the 1980s, Australia began integrated the service system of early childhood education and care. The Australian government invested about more than 160 million Australian dollars in early childhood education and care in recent years [2]. This study was to investigate the current workforce training on early childhood education and care in Australia, looking forward to learn some useful experience from workforce training on early childhood education and care in Australia.
\end{abstract}

\section{Overview of the Australian Childhood Education and Care}

In Australian, education is the mainly responsibility of the states and territories. State or territory government funding and management of public and private schools in their jurisdiction, the federal government provides financial support for public universities. The range of early childhood education and care services in Australia are 0-8 years old children. Broadly speaking, the federal government is responsible for the system of early childhood care, while the states and territories are responsible for the system of early childhood care education.

Preschool education is not compulsory education in Australia, and its management is relatively loose. The Australian Government does not provide universal early childhood education and childcare services. Almost most of the child care centers are private. Only a few belong to the public free of child care services. But most of early childhood education (preschool) are government-sponsored. In recent years, greatly increase in demand for early childhood education in Australian for the reason of woman's employment growth plus the accept of non-parental education for young children from the parents, leading to early childhood care and education services appear more messy phenomenon. The main problems are: there are less than early childhood care services resources for the special needs children and infants in some regions; Many child care services sector provide poor development and learning opportunities for children, and many service personnel have poor qualification and experience; Child care costs continue to increase, the families and government has also increased the financial burden. But generally speaking, the Australian early childhood education and care services in accordance with international standards, it is still considered a good development and distribution, and the degree of participation of young children is also high[3]. While its federally funded and national implemented of Quality Improvement and Accreditation Scheme even be considered a model of global best practices [4]. 


\section{Early Childhood Education and Care Workforce Training Policy in Australian}

Australia are currently undergoing a complete set of systematic efforts to enhance the quality of early childhood education and childcare services. For example, the National Quality Framework which formulated by the Council of Australia Government (referred to COAG) is an important guide. The national quality framework provisions that before 2013, the staff who all directly involved in the education and care of young children need to obtain a minimum of Children's services Certificate III; and all early childhood education and care programs need to have a teacher with a degree [5].

The high quality of professional workforce is considered to be the important driving force that high-quality early childhood education and childcare services, so the Australian government attaches great importance to to improve the quality of early childhood education and care workforce. For example, the federal government is on the Increase manpower supply and take some measures such as expansion of university enrollment class. The state and territory governments will provide funding for professional practitioners in education, training, etc., and assist the professional practitioners on work and learning. Currently, in addition to proposed Early Years Workforce Strategy, Australian also proposes other specific policies such as funding education, the expansion of Additional early childhood education university places, Innovative Early Childhood Workforce Projects. The specific circumstances described below:

\section{Early Years Workforce Strategy}

The Strategy builds on Investing in the Early Years - A National Early Childhood Development Strategy, which was endorsed by the Council of Australian Governments (COAG) in July 2009. The vision of the Early Childhood Development (EDC) Strategy captured the aspirations of governments that by 2020 all children will have the best start in life to create a better future for themselves and for the nation. The Strategy focuses on immediate priorities for the ECEC workforce and complements existing Australian Government and state and territory government measures, while setting a long-term strategy that focuses on supporting more integrated ways of working across the ECD sector.

The Strategy addresses five key areas relevant to early childhood education and care:

Providing a professional early childhood education and care workforce; Ensuring a growing workforce to continue to meet community demand; Aiding early childhood educators to gain the qualifications and skills the workforce needs to continue to provide high quality care; Fostering the creation of a responsive workforce, one which can address the needs of all children; Facilitate collaboration among-st members of the broader early childhood development workforce.

\section{Funded Training}

In funding early childhood education and care services staff training, the government mainly take the following three actions at present :

\section{Recognize of Prior Learning}

This measure will reduce the overall time spent on these people, and to be promoted in terms of qualified personnel to meet the minimum eligibility requirements established by the national quality framework. For the implementation of this policy, the specific practices are as follows:

Draw up the new national testing tool to test the certificate III that in the field of children's services, diploma and advanced diploma; Training of inspectors and use the testing tool; Offer acceptance testing costs subsidies for early childhood education and care services staff who from the rural and remote areas.

\section{Higher Education Loan Program}

The allowance is design for early childhood teachers that from high need area. The intention is to reduce their burden of debt on Higher Education Loan Program (referred HELP). The maximum subsidy amount of each year for preschool workers are \$ 1,795.41 in 2012-2013. 


\section{Removal of Technical and Further Education Fees}

The policy is serving the early childhood care staff, aimed at helping them eliminating the cost of learning, obtain the diploma and advanced diploma in child care specialist.

\section{Additional Early Childhood Education University Places}

The Australian government is committed to universal preschool education, Australia needs more teachers who are in college education to achieve this goal. This measure would expand university enrollment on early childhood education programs, so that more students who are interested in early childhood education can obtain teaching qualifications.

\section{Innovative Early Childhood Workforce Projects}

The Australian government develop this project which contains seven plans in July 2009:Building partnership between multifunction Aboriginal Children's Services (MACS) and non-Aboriginal child care centers; Three Sisters Plan; Early education and primary teacher workforce development strategy for children in Northwest; Linking and Learning Program; Establish courses circle to increase education leadership; Early childhood training and culture-related education; Aboriginal Early Learning Framework funded projects. The Government provided a total of \$500,000 in one-time seed money for early education and childcare professionals to explore best practices and innovative models, in order to retain these professionals in early childhood education, and further enhance their ability to work. The implementation of the scheme was a great success. May 2010, the Australian government provides a second one-time seed money. It aims through the development of best practices or innovative models to enhance early childhood education and care services manpower quality.[6]

\section{Enlightenment}

\section{Complete Kindergarten Teachers' Professional Qualification Certification System}

Currently our kindergarten teachers' qualification rate is low, more teachers have on certificate. Especially in the vast rural kindergarten, most of teachers have no qualifications, no professional training, no formal status of teachers, and no teachers' titles[7].here are also a lot of no formal qualifications staff, and they have low social status in Australia's remote, disadvantaged areas and indigenous communities. The Australian government has taken, such as "Recognize of Prior Learning" and other measures, divided into three levels of the qualification services for children, which can help them obtain appropriate qualification certificates in a short time.

We can learn from the Australian experience developing advanced stages of kindergarten teachers qualification system, improve the qualifications of kindergarten teachers species. We can divided into teachers certification based on "Teacher Professional Development Stages" , the first level is relatively loose primary level, only to examine whether there is compliance with the requirements of professional credits, so as to ensure that teachers meet the basic requirements.

The second level is moderately stringent qualification, this level can review all kinds of graduates of teacher education institutions through teacher training qualification, examined whether their professional knowledge and skills reach the standards. The third level is the more stringent level, aimed at the selection of the outstanding senior teachers, their teaching practice, education and research capacity and other aspects of moral excellence have to achieve excellence.[8].Such classification qualification can be solved in remote, poor areas of kindergarten teachers "embarrassed" teacher identity, it can contribute to stable local preschool teachers.

\section{Innovative Funding Models of Preschool Teacher Training}

"The several opinions on the current development of preschool education under the state council" in 2010 clearly stated: We should create variety of ways to speed up childhood education teachers building, building a noble morality, love of children, excellent service, reasonable structure of preschool teachers. To this end, countries have also introduced such as "Midwest kindergarten 
teacher national training program" and other relevant policies and special funding preschool teacher training programs. While these policies improve the funding of kindergarten teachers' Professional accomplishment, to promote the professional development of preschool teachers. But we should be clearly aware that, funding for early childhood teacher training is not enough, we still has not formed a complete system of funding, the early childhood teacher training funding model is still relatively simple, we cannot take care of all the needs of trained teachers.

Australian government had taken various measures to improve the funding system for kindergarten teachers. Such as "Higher Education Loan Program”, the allowance is design for early childhood teachers that from high need area. The intention is to reduce their burden of debt on Higher Education Loan Program. There are also the "Additional early childhood education university places" and "Removal of Technical and Further Education Fees" policies. We can learn from the Australian government's approaches, innovative funding model of preschool teacher training: Such as for remote and kindergarten teachers, we can set up the relevant training institutions exclusively preschool correspondence courses in poor areas, introduced specific policies to be funded, reduction of the cost of training kindergarten teachers, to help them improve their education, to obtain the corresponding teacher certification. For teacher certification, we can accept the introduction of relevant policies to provide certification testing cost subsidies for the rural and kindergarten teachers in remote areas. Meanwhile, in order to encourage innovation and early childhood teacher training model, we can also learn from the Australian government's approach to set up a seed fund dedicated to financing committed to early childhood teacher training model innovation preschool workers.

\section{Acknowledgment}

This research was financially supported by Scientific and Technological Research of Chongqing Municipal Education Commission Program: "Study on Models of Universal Preschool Education in Poor Counties in Chongqing (KJ1401417)”.

\section{References}

[1]Marshall, Nancy L., Dennehy, Julie, Starr,Elizabeth and Robeson,Wendy Wagner (2005). Preparing the Early Education and Care Workforce: The Capacity of Massachusetts. Institutions of Higher Education. Center for Research on Women, Wellesley College.

[2]Weintraub, Hillel (2012). Early Childhood Education and Care in Australia. Information onhttp://www.childresearch.net/index.html

[3]Guohua, He(2013). Discussion on Australian workforce training of early childhood education and care. The journal of Childhood Education and Care research(10).

[4] Elliott, Alison(2006).Early childhood education: Pathways to quality and equity for all children. Camberwell, Victoria: ACER Press.

[5]Green, Nicole C. \& Nolan, Andrea (2011). Preparing the Australian early childhood workforce for rural and remote settings: A review of the literature. Australian Journal of Teacher Education, 36 (12), 83-96.

[6][8]Hailei,Peng(2012).American Kindergarten Teacher Qualification and Certification System and Its Implications.Journal of Preschool education(Educational Sciences)(12).

[7]Jianrong, Chen.\& Zhongjun, Bai(2010). Regional childhood education teachers Predicament and the Way Out.Journal of the Chinese society of education(8). 